\title{
Ecology of Thysanoptera within Cabbage Fields
}

\author{
R. C. NORTH AND A. M. SHELTON \\ Department of Entomology, New York State Agricultural Experiment Station, \\ Cornell University, Geneva, New York 14456
}

\begin{abstract}
Environ. Entomol. 15: 520-526 (1986)
ABSTRACT The occurrence and species composition of thrips within cabbage fields were studied during 1981 and 1982 . Temporal differences in abundance and species composition depended on the spatial relationship of cabbage fields to cereal and forage crops. Sticky traps within cabbage fields recorded peak flights of thrips during maturation and senescence of adjacent wheat or oat fields and cutting of adjacent alfalfa and red clover fields. These data indicate several important findings regarding the ecology of thrips in general and the possible management of Thrips tabaci Lindeman in particular. First, although there are large numbers of thrips in cabbage fields during certain time periods (e.g., maturation or harvesting of crops), most will not be $T$. tabaci and need not be of concern to cabbage growers. Second, there are significant differences in thrips phenology and species composition in cabbage fields, and these differences appear to be dependent on phenology and management of adjacent field and forage crops. Third, although many other species are present, $T$. tabaci appears to be present in adequate numbers to infest cabbage at the critical period of head formation. This critical period occurs at different times depending on area, planting date, variety, and weather.
\end{abstract}

THE ONION THRIPS, Thrips tabaci Lindeman, has become one of the chief pests of New York's annual 5,000 ha of harvested cabbage. The damage caused by $T$. tabaci feeding appears as a bronze discoloration and rough texture on the head leaves and results in cabbage that does not meet fresh market standards. Because of the potential for injury by $T$. tabaci, the difficulty in controlling them once they move into the head, and the difficulty in identifying them in the field, growers fear the presence of any thrips species on the plant. This fear has led to prophylactic insecticide treatment of much of the cabbage in this area.

To effectively control $T$. tabaci by insecticidal measures, we must understand the ecology of this multivoltine and polyphagous insect. In a previous study (Shelton \& North 1986), we examined the species composition and occurrence of Thysanoptera within early season field crops (wheat, oats, alfalfa, and red clover) that were adjacent to cabbage fields. In that study, we noted shifts in species composition on these field crops through time, and we attributed these changes to changes in habitat structure (e.g., maturation and senescence in wheat and oats, and cropping practices in alfalfa and red clover). We noted T. tabaci in all these field crops and suspected that these crops may serve as a reservoir for $T$. tabaci, which may later infest cabbage.

As a corollary to the previous study on species composition and occurrence in field crops, the present study was undertaken to determine the movement in time and space of Thysanoptera populations within and into adjacent cabbage fields. In this study, particular emphasis is placed on $T$. tabaci because this is the species that causes damage to cabbage (North \& Shelton 1986).

\section{Materials and Methods}

In 1981, 12 cabbage fields in Ontario County, N.Y., were monitored for thrips populations from June through harvest in September and October. In 1982, seven cabbage fields in Ontario County and five cabbage fields in adjacent Monroe County were monitored from July through harvest in October and November. Aerial counts of adult Thysanoptera were obtained weekly from three white traps per field, each trap with a surface area $(425$ $\mathrm{cm}^{2}$ ) coated with Tanglefoot (Shelton \& North 1986). These traps provided a cylindrical trapping surface so that movement into the trap on a horizontal plane would not be influenced by cardinal direction. Aerial traps were adjusted weekly to be $0.25 \mathrm{~m}$ above the crop canopy. Traps were placed in a line, with one trap in the center of the field and the other two equidistant from the center of the field.

Cabbage fields selected for this study were adjacent to the field crops reported in the previous study (Shelton \& North 1986). Since several cabbage fields in the present study were adjacent to more than one cereal or forage crop, we designated six systems for presentation of the thrips population trends in cabbage: system 1, cabbage fields surrounded by only a wheat field; system 2 , cabbage fields surrounded by one wheat and one oat field; system 3, cabbage fields surrounded by an alfalfa field; system 4, cabbage fields surrounded by an oat field; system 5 , cabbage fields surround- 

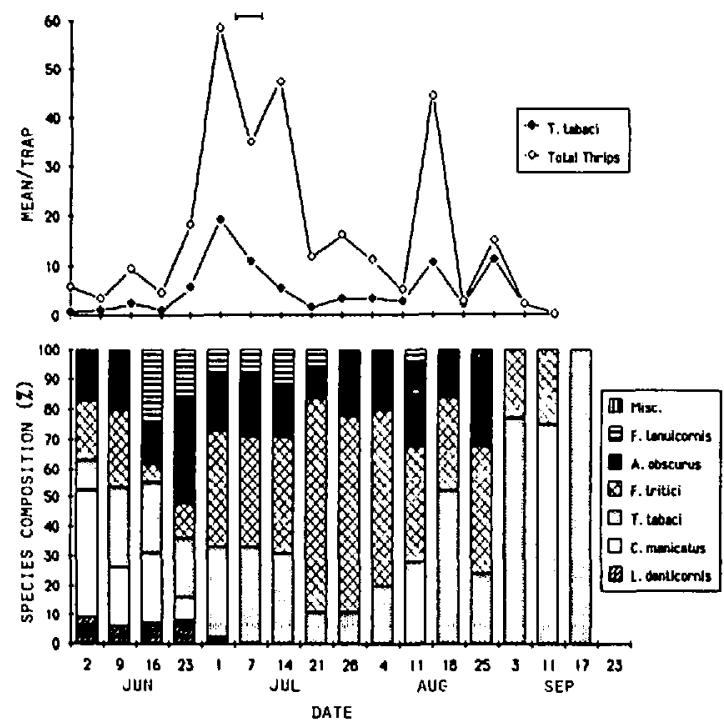

Fig. 1. Means and species composition of thrips collected from sticky trap samples from three cabbage fields in 1981, Ontario County, system 1. adjacent wheat field.

ed by one wheat and alfalfa field; and system 6 , cabbage fields surrounded by a red clover field. In addition to classifying the data on thrips populations by this method of crop systems, data are separated by county and year. All data presented are the mean number of thrips per trap from an individual or series of cabbage fields surrounded by a certain set of field crops.

\section{Results and Discussion}

All the terebrantian thrips species listed in Shelton \& North (1986), except Aptinothrips rufus (Gmelin), Hercinothrips femoralis (O. M. Reuter), and Sericothrips spinear floridanus (Watson), were collected on sticky traps in cabbage fields in 1981 and 1982. The majority of thrips collected in cabbage comprised six of the seven most abundant thrips collected from cereal and forage crops. These were Limothrips denticornis (Haliday), Chirothrips manicatus Lindeman, Frankliniella tritici (Fitch), Anaphothrips obscurus (Müller), Frankliniella tenuicornis (Uzel), and $T$, tabaci. Adjacent crops and their phenology significantly influenced the relative abundance and adult composition of thrips collected.

System 1 . The means of all thrips adults and $T$. tabaci captured per sticky trap per week in three cabbage fields in 1981 are shown in Fig. 1. Trends of total thrips and T. tabaci appear to have been similar, which indicates a general thrips movement. The peak trap catch in cabbage corresponds well to the time of senescence of the surrounding wheat fields. Thus, by the time the alfalfa fields were harvested (9-16 July), thrips movement into cabbage fields was declining. The peak catch the
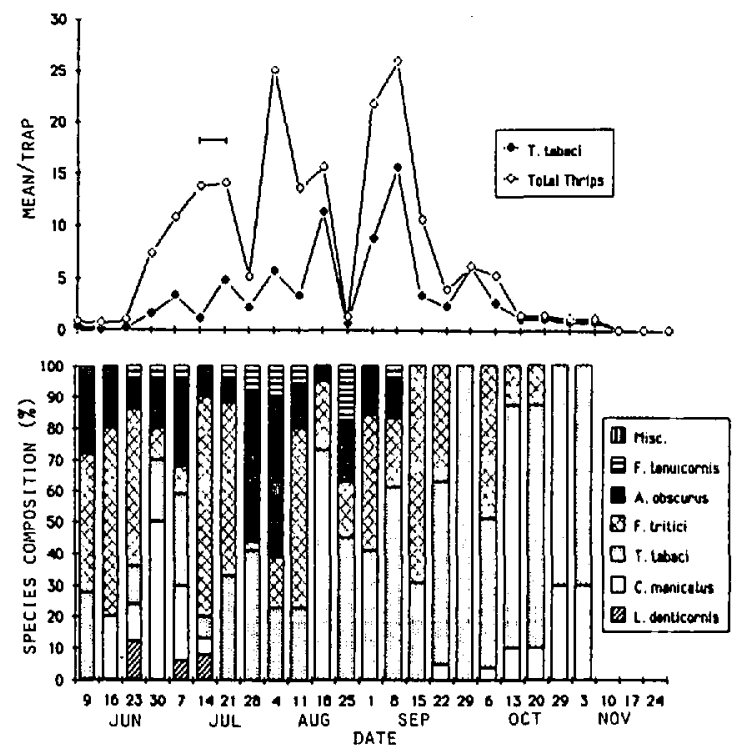

Fig. 2. Means and species composition of thrips collected from sticky trap samples from three cabbage fields in 1982, Ontario County, system $1 . \longmapsto$, harvest of adjacent wheat field

week of $1-7$ July $(\bar{x}=58.3$ per trap) consisted of four species. The proportion of $T$. tabaci and $F$. tritici was relatively equal during that time, but F. tritici dominated during the later part of July through 1 August. A. obscurus was also well represented during June, July, and August, and the trap catch during the week of $18-25$ August was almost evenly divided among the three species.
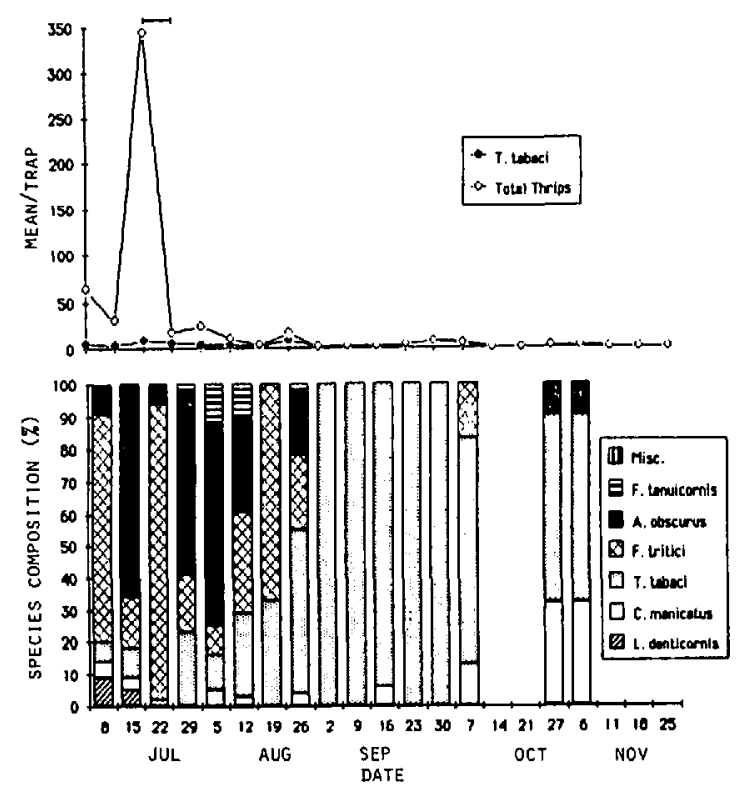

Fig. 3. Means and species composition of thrips collected from sticky trap samples from one cabbage field in 1982, Monroe County, system 1. adjacent wheat field. 

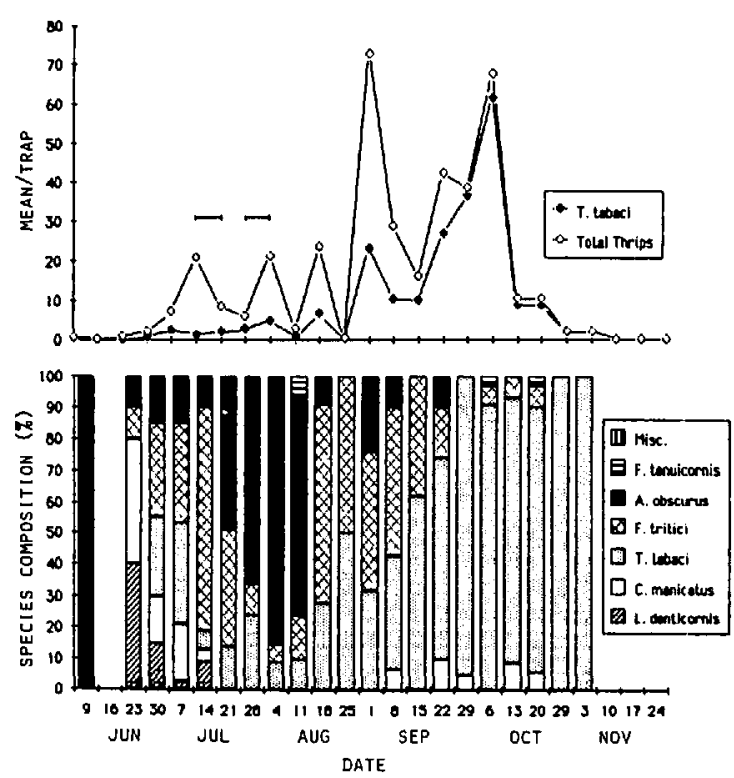

Fig. 4. Means and species composition of thrips collected from sticky trap samples from two cabbage fields in 1982, Ontario County, system 2. 2 harvest of adjacent wheat and oat fields.

The means of thrips collected on sticky traps over cabbage in Ontario and Monroe counties in 1982 are shown in Fig. 2 and 3, respectively. Within Ontario County, the adjacent wheat fields were harvested the week of 14-21 July. There was a rise in the counts in the three cabbage fields during that time, but the peaks were not reached until the week of 28 July- 4 August $(\bar{x}=28$ per trap) and 1-8 September ( $\vec{x}=25.9$ per trap). $T$. tabaci and $F$. tritici were the predominant thrips captured throughout the season, but during the weeks preceding the first large peak (28 July-4 August), A obscurus was the most abundant thrips. Trends of $T$. tabaci populations followed trends of total thrips. The low numbers recorded during the weeks of 18-25 August and 15-22 September may have been the result of unfavorable environmental conditions. In Monroe County (Fig. 3), the wheat fields were harvested the week of 22-29 July. The highest mean yet observed ( $\bar{x}=344$ per trap) was recorded from one cabbage field 1 week before wheat harvest, and the vast majority of these thrips were $F$. tritici. Because of this peak, a somewhat distorted representation of the abundance of thrips captured on sticky traps throughout the season is presented. Relative to the other cabbage fields in system 1, thrips were nearly as abundant throughout the rest of the season. The months of September and October were dominated by T. tabaci, whereas $A$. obscurus and $F$. tritici alternated in being in the majority before September.

The oscillations recorded over cabbage by sticky traps in both years are well correlated with the peaks and valleys recorded for adjacent wheat fields (Shelton \& North 1986). The last peak in cabbage

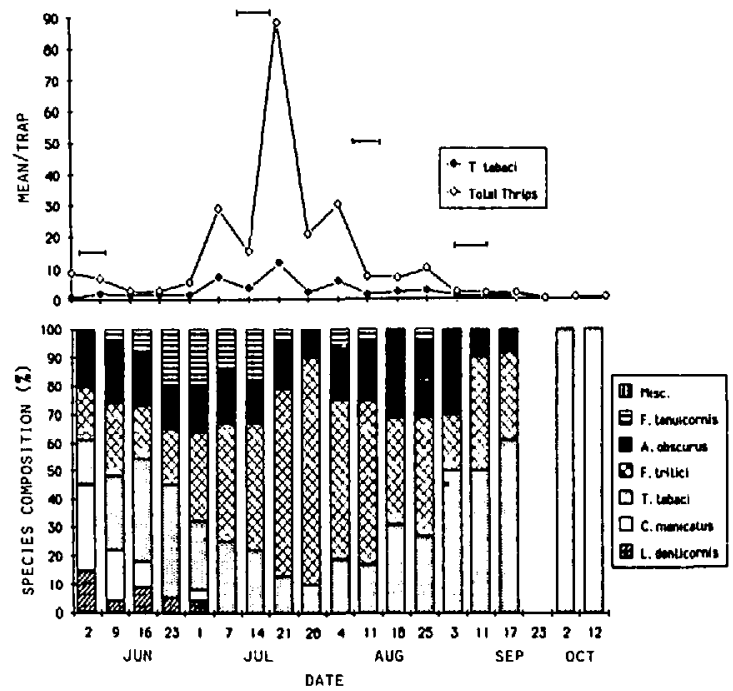

Fig. 5. Means and species composition of thrips collected from sticky trap samples from five cabbage fields in 1981, Ontario County, system 3 . adjacent alfalfa field.

in 1981 (Fig. 1) does not have a similar peak in wheat because no sampling was done. The peaks in early to mid-August and early September in Ontario County in both cabbage (Fig. 2) and adjacent wheat fields may have been the result of movement of $F$. tritici and $T$. tabaci to and from volunteer wheat, cabbage, and other as yet undiscovered sources. It is possible that alfalfa and hay fields within several kilometers were being cut and
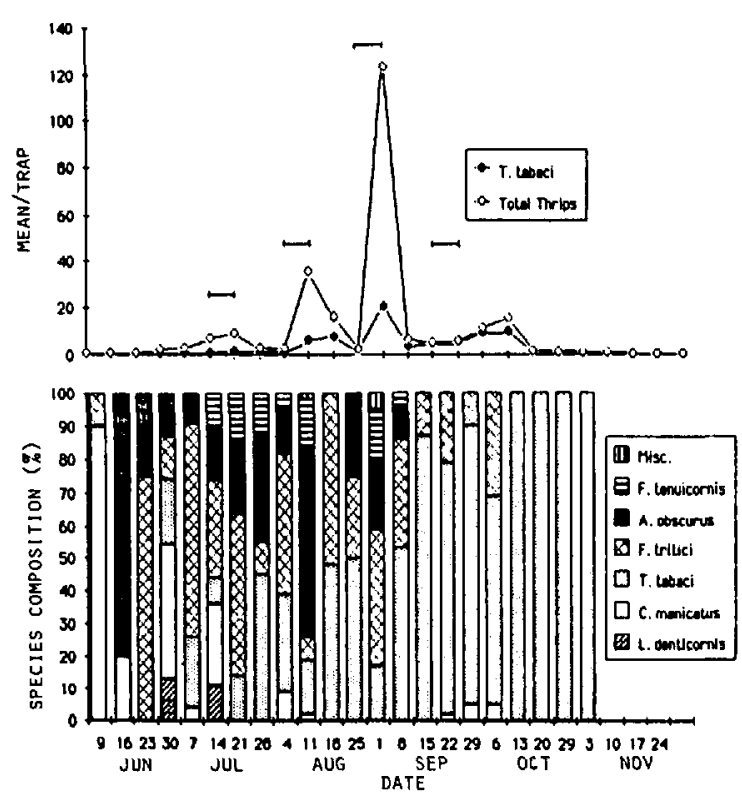

Fig. 6. Means and species composition of thrips collected from sticky trap samples from two cabbage fields in 1982, Ontario County, system 3. adjacent alfalfa field. 

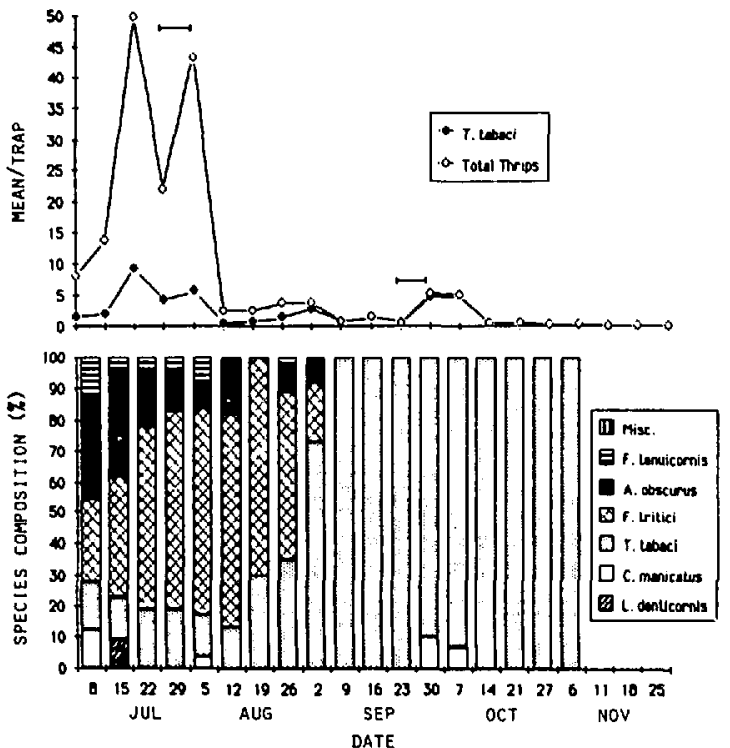

Fig. 7. Means and species composition of thrips collected from sticky trap samples from one cabbage field in 1982, Monroe County, system 3. $\longmapsto$ harvest of adjacent alfalfa field.

large numbers of thrips were moving with the prevailing winds. However, this phenomenon was not apparent in Monroe County in 1982 (Fig. 3) to help substantiate this hypothesis. A precipitous drop in the counts during the week of 18-25 August 1982 in Ontario County was recorded in both wheat and cabbage. An examination of weather data reveals that on 6 of the 8 days some precipitation was recorded in the area, and our previous observations have indicated a dramatic decline in thrips catches during storm conditions.

System 2. The wheat/oat/cabbage system in Ontario County is presented in Fig. 4. The first peak from the two cabbage fields occurred the week of 7-14 July and corresponds to the harvesting of wheat during the week of 14-21 July. The second peak, 28 July-4 August, corresponds to the harvesting of oats, 4-11 August. Another peak of similar magnitude occurred 1 week later. The highest mean was recorded during the week of 25 August-1 September $(\bar{x}=\mathbf{7 2 . 4}$ per trap). The oscillations continued with another large peak during the week of 29 September- 6 October $(\bar{x}=67.3$ per trap). The first peak was dominated by $F$. tritici, the second by $A$. obscurus, the third by $F$. tritici and T. tabaci, the fourth by F. tritici, and the fifth by $T$. tabaci. Although the peaks in the cabbage fields are of a lower magnitude, they are almost the mirror image of those recorded for wheat and oat fields in Ontario County (Shelton \& North 1986). There is also an excellent correlation between the species collected from wheat and oat fields and those collected over adjacent cabbage fields.

The large number of $T$. tabaci captured on sticky
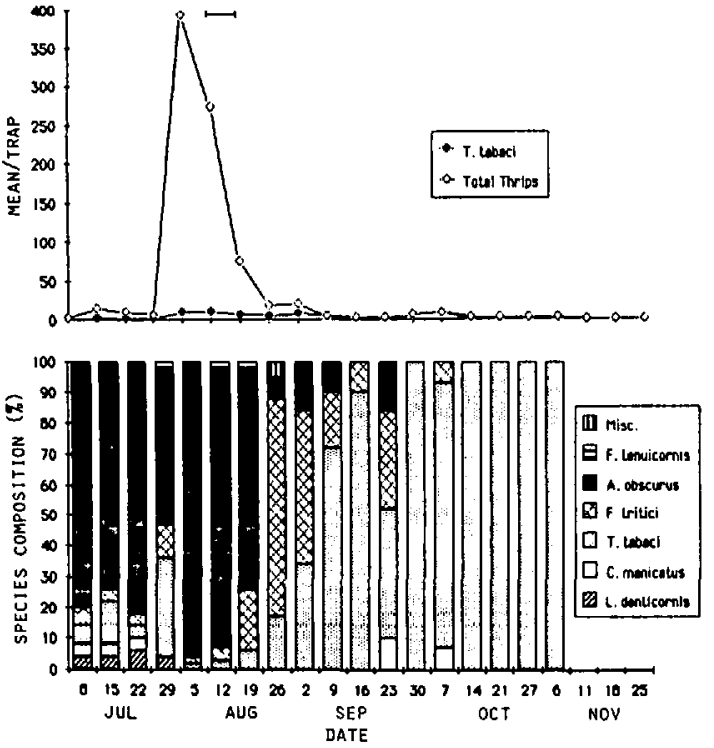

Fig. 8. Means and species composition of thrips collected from sticky trap samples from two cabbage fields in 1982, Monroe County, system 4. adjacent oat field.

traps in late September and early October may have originated from the cabbage fields. This increase in $T$. tabaci was only recorded in Ontario County within cabbage fields next to volunteer wheat and oat fields, and our samples of volunteer wheat and oat fields do not support the hypothesis that $T$. tabaci adults originated from these crops. The majority of cabbage fields in Ontario County are grown for processing (sauerkraut) and are less
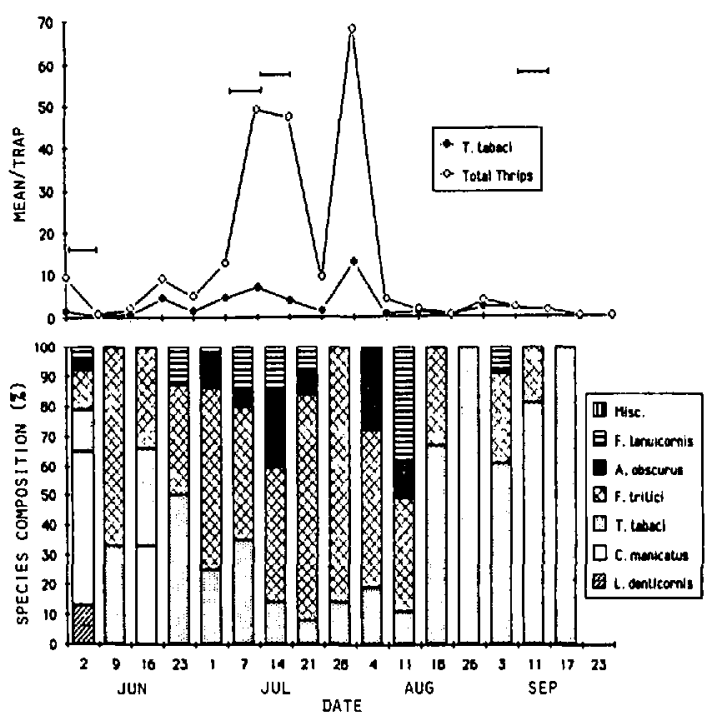

Fig. 9. Means and species composition of thrips collected from sticky trap samples from one cabbage field in 1981, Ontario County, system 5. adjacent wheat or alfalfa field. 
likely to be treated with insecticides than the fresh market cabbage grown in Monroe County. Thus, a buildup of $T$. tabaci populations within untreated cabbage fields may occur. Untreated cabbage may contain significant populations of $T$. tabaci on the frame leaves and within the head during September (North \& Shelton 1986).

System 3. Eight cabbage fields were analyzed, five in Ontario County in 1981, two in Ontario County in 1982, and one in Monroe County in 1982. In 1981 in Ontario County, the cabbage fields adjacent to alfalfa harbored the most thrips during July and August (Fig. 5), and the majority of these were $F$. tritici. The peak count during the week of 14-21 July ( $\bar{x}=87.7$ per trap) corresponded to the cutting of adjacent alfalfa fields. Alfalfa was also cut during the first week of June, the second week of August, and the second week of September without producing major changes in the number of thrips collected on the sticky traps in cabbage. T. tabaci populations followed the same trends as total thrips populations.

In 1982 in Ontario County, one moderate and one large peak are present (Fig. 6). Alfalfa was cut the weeks of 14-21 July, 4-11 August, 25 August1 September, and 22-29 September, and these periods correspond well to increases in trap counts. Peak thrips counts occurred the week of 25 July1 August $(\bar{x}=122.5$ per trap). No one species dominated during the first three cuttings of alfalfa, whereas $T$. tabaci was the predominant species during the fourth and final cutting.

Within the cabbage field in Monroe County (Fig. 7), thrips counts on sticky traps were highest from mid-July until the first week of August, with a peak the week of $15-22$ July $(\bar{x}=49.7$ per trap). The adjacent alfalfa field was cut during the weeks of 27 May-3 June, 29 July-5 August, and 23-30 September. As was the case in Ontario County, there is a good correspondence between increases in trap counts and the cutting of alfalfa. F. tritici dominated the second and perhaps part of the third cutting period, but $T$. tabaci predominated the rest of the season.

The peaks in thrips populations over cabbage correspond well to those recorded in adjacent alfalfa fields in both counties and years, and the species composition over cabbage is also well correlated with the thrips within and over alfalfa (Shelton \& North 1986). In both 1981 and 1982, the large peaks in total thrips in Ontario and Monroe counties correspond to the cutting of adjacent alfalfa fields. T. tabaci adults captured on sticky traps also were at their maximum during that time period, but were of a lower magnitude than those peaks recorded from cabbage fields adjacent to wheat and oat fields (system 2). In September, the large peak observed in Ontario County in systems 1 and 2 is absent. Perhaps alfalfa may not be a good reservoir for T. tabaci for nutritional reasons, or conversely, adult $T$. tabaci may remain within the crop canopy and do not leave. Shirck (1951)

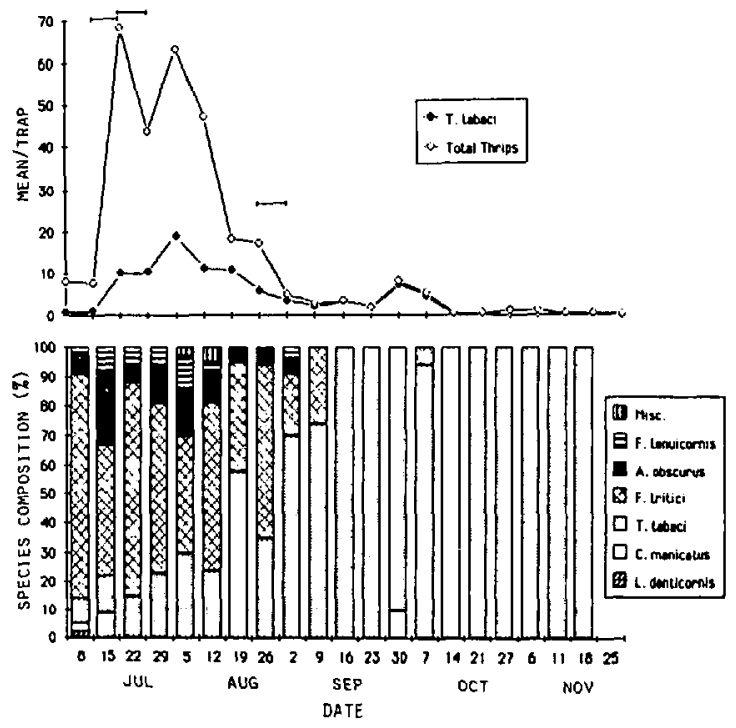

Fig. 10. Means and species composition of thrips collected from sticky trap samples from one cabbage field in 1982, Monroe County, system 5. of adjacent wheat or alfalfa field.

thought that $T$. tabaci adults infesting onion fields originated from alfalfa, clover, or other sources, but Harding (1961) reported that concentrated migrations into onion fields did not occur in South Texas. A more detailed study in Iowa by Wolfenbarger \& Hibbs (1958) of thrips movement from wheat and alfalfa resulted in circumstantial evidence that these crops were the sources of thrips infestations in cabbage.

System 4. Two cabbage fields adjacent to oat fields were monitored in Monroe County in 1982 (Fig. 8). Both oat fields were harvested the week of 12-19 August. This corresponds well to the ripening and drying down of the oats and the subsequent movement of thrips into the adjacent cabbage fields. The peak flight $(\bar{x}=392.8$ per trap) during the week of 29 July-5 August consisted mainly of A. obscurus. T. tabaci and F. tritici were collected in moderate numbers throughout the rest of the season.

This quick buildup and crash of A. obscurus adult populations was also observed within and over oat fields (Shelton \& North 1986). The species composition of the thrips collected on the sticky traps fluctuated in a similar way within and over oat and cabbage fields.

The increase in $T$. tabaci populations observed with cabbage fields that are adjacent to oat and wheat fields in Ontario County was absent. Even with volunteer oats available for reproduction and movement of $T$. tabaci adults to adjacent cabbage, T. tabaci populations remained low. This may be due to insecticide applications within cabbage fields or some other phenomena.

System 5. The results from the wheat/alfalfa/ 


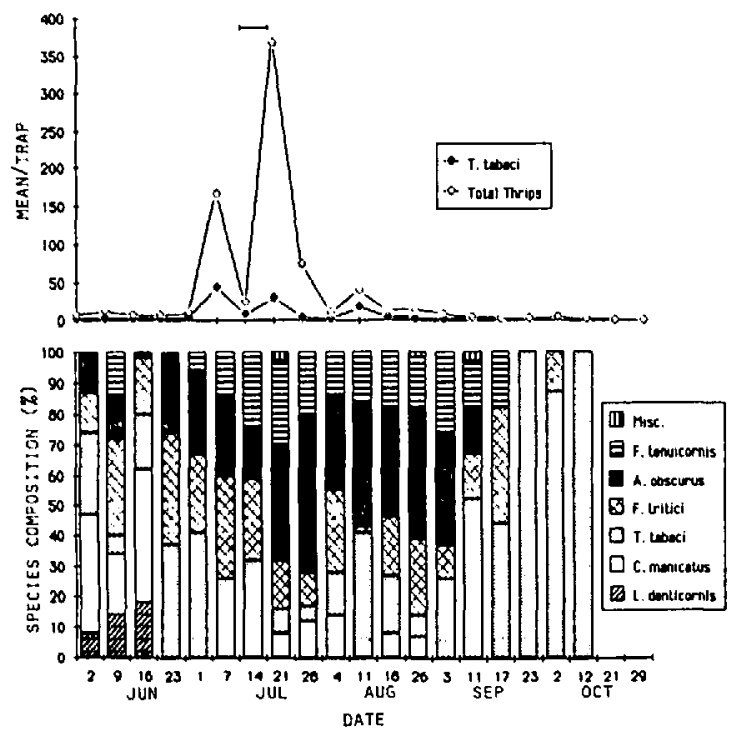

Fig. 11. Means and species composition of thrips collected from sticky trap samples from one cabbage field in 1981, Ontario County, system 6. of adjacent red clover field.

cabbage system delineated in 1981 in one cabbage field are shown in Fig. 9. The wheat field was harvested during the week of 9-16 July and an alfalfa field was cut during the following week, 16-23 July. Two other alfalfa cuttings were recorded, 2-9 June and 11-17 September. The peak catch of total thrips $(\bar{x}=68$ per trap) occurred during the week of 28 July-4 August, and most of the thrips caught during the sampling period were $F$. tritici. $T$. tabaci populations peaked the week of 28 July-4 August and became the dominant species captured during fall.

Trap counts from a cabbage field adjacent to alfalfa and wheat in 1982 in Monroe County (Fig. 10) are reasonably well correlated with harvesting or cutting of an adjacent wheat field with a peak during the week of $22-29$ July ( $\bar{x}=68.3$ per trap). The wheat field was harvested the week of 22-29 July with the alfalfa cutting taking place the weeks of 27 May-3 June, 15-22 July, and 26 August-2 September. The majority of thrips collected were F. tritici, especially during July through mid-August. $T$. tabaci populations were highest in July and August, and it was the most abundant species throughout the rest of the sampling period.

In 1981, peaks found over the adjacent alfalfa and wheat fields (Shelton \& North 1986) were similar to those recorded from cabbage. The peak over cabbage during the week of 28 July-4 August was present in all three crops, and the species composition was similar. Similar results were observed for the wheat, alfalfa, and cabbage fields in Monroe County in 1982.

System 6. The results of the red clover/cabbage system are presented in Fig. 11. Two sharp increases in thrips populations were observed. The larger peak $(\bar{x}=365.7$ per trap) was recorded on 21 July and corresponded to the cutting of red clover during the week of 16-23 July. No one species of thrips predominated during the season, but during the first and second peaks, $T$. tabaci, $F$. tritici, $A$. obscurus, and $F$. tenuicornis were present in relatively the same proportion.

The first peak over cabbage did not have a companion peak over red clover, but there was a large buildup of adults collected in the foliage at that time (Shelton \& North 1986). The magnitude of the peaks over cabbage was greater than that recorded within the red clover field. The trap counts within the other cabbage fields were less than those recorded within an adjacent cereal or forage crop. We have no adequate explanation available for this phenomenon, since the species composition over both crops is well correlated and we doubt that an influx of thrips from some other source was involved. T. tabaci populations were highest during July and clearly dominated the counts within cabbage fields a few weeks before harvest.

These collective data from cabbage fields adjacent to several field or forage crops indicate several important findings. First, large numbers of thrips in cabbage fields during certain time periods (e.g., harvesting or cutting of crops) may not be $T$. tabaci and need not be of concern to cabbage growers. Second, there are significant differences in the occurrence of thrips and species composition in cabbage fields, and these differences appear to be dependent on the phenology and management of adjacent field and forage crops. Third, although many other species are present, $T$. tabaci appears to be present in adequate numbers to infest cabbage at the critical period of head formation. This critical period occurs at different times depending on area, planting date, variety, and weather.

Cabbage in Monroe County is grown primarily for fresh market and storage purposes and must conform to strict USDA grade standards. Most of the cabbage from Monroe County is phenologically at least a month behind that of Ontario County and, thus, will apparently not become infested during head formation by thrips moving from wheat or oats. Thrips populations from wheat and oats that infest cabbage frame leaves before cabbage head formation can be reduced with foliar insecticides, thus preventing those populations from moving into the head. Once cabbage begins to form a head, control is reduced because thrips become sheltered in the head. For cabbage that begins to head in mid- to late August, growers should be concerned about thrips that may move from neighboring fields of alfalfa that are harvested. Thus, Monroe cabbage growers should be cognizant of the stage of surrounding field and forage crops, as well as the stage of their cabbage.

Because cabbage is grown in Ontario County primarily for processing (sauerkraut), it must con- 
form to the less stringent cabbage processing standards. Thus, although the cabbage in Ontario County may be more vulnerable to colonization because of higher numbers of $T$. tabaci from wheat during the cabbage heading stage, insecticides, resistant varieties (Shelton et al. 1983), and a defect action level for thrips in the final product (Shelton et al. 1982) may allow for adequate control.

Since it now appears to us that $T$. tabaci is moving from cereal or forage crops to adjacent cabbage fields, future work will be directed to predicting the risk of infestation in individual cabbage fields based on the temporal and spatial dynamics of surrounding field and forage crops.

\section{Acknowledgment}

We thank W. T. Wilsey for field assistance and S. Nakahara (Systematic Entomology Lab., USDA) for assistance in thrips identification. We also thank D. F. Cox (Dep. of Statistics, Iowa State Univ.) for his timely assistance with the statistical analysis.

\section{References Cited}

Harding, J. A. 1961. Effect of migration, temperature, and precipitation on thrips infestations in south Texas. J. Econ. Entomol. 54: 77-79.
North, R. C. \& A. M. Shelton. 1986. Colonization and intraplant distribution of Thrips tabaci (Thysanoptera: Thripidae) on cabbage. J. Econ. Entomol. 79: 219-224.

Shelton, A. M. \& R. C. North. 1986. Species composition and phenology of Thysanoptera within field crops adjacent to cabbage fields. Environ. Entomol. 15: 513-519.

Shelton A. M., J. R. Stammer, W. T. Wilsey, B. 0. Stoyla \& J. T. Andaloro. 1982. Onion thrips (Thysanoptera: Thripidae) damage and contamination in sauerkraut. J. Econ. Entomol. 75: 492-494.

Shelton A. M., R. F. Becker \& J. T. Andaloro. 1983. Varietal resistance to onion thrips in processing cabbage. J. Econ. Entomol. 76: 85-86.

Shirck, F. H. 1951. Hibernation of onion thrips in southern Idaho. J. Econ. Entomol. 44: 1020-1021.

Wolfenbarger, D. \& E. T. Hibbs. 1958. Onion thrips (Thrips tabaci Lind.) infesting cabbage. J. Econ. Entomol. 51: 394-396.

Received for publication 26 February 1985; accepted 27 January 1986. 